\title{
Uso do software Winplot para o estudo de Trigonometria
}

\author{
Avani Maria Calmon Rocha*
}

\begin{abstract}
Resumo
O uso de novas tecnologias na escola pode reforçar a tentativa constante de solução das dificuldades encontradas no ensino da Matemática em qualquer nível de ensino, proporcionando uma motivação diferente das aulas teórico-expositivas e também trabalhando com o lado intuitivo de cada aluno. Para incorporar esse recurso no processo de ensino e aprendizagem, várias estratégias têm sido adotadas. Uma delas é o desenvolvimento e aperfeiçoamento de softwares educacionais que oferecem instâncias físicas em que podem ser feitas manipulaçóes diretas sobre diferentes representações visuais apresentadas na tela do computador, o que não ocorre com o uso do lápis e papel ou do quadro. Tal método permite ao aluno ver algumas importantes características e/ou propriedades dessas representaçóes, além de tornar a aula mais dinâmica e lúdica, estimulando o grupo e despertando o interesse, modificando significativamente o papel do professor no processo de aprendizagem. Dentro desse contexto, destaca-se, neste artigo, como o professor de Ensino Médio pode fazer uso do software educacional Winplot, em construçôes geométricas para visualização dos conceitos e propriedades relacionadas às funçóes trigonométricas.
\end{abstract}

Palavras-chave: novas tecnologias, software educacional, trigonometria.

\section{Use of Winplot software to Trigonometry study}

\begin{abstract}
The use of new technologies in schools could help to resolve the constant difficulties encountered in teaching Mathematics at all levels and thereby motivate students differently from the theoretical-expository model and also work with the intuitive side of each student. A variety of strategies have been adopted to incorporate this feature into the teaching and learning process. One such is the development and improvement of educational software which provide physical instances in which direct manipulation of different visual representations can be presented on the computer screen. This enables students to see certain important characteristics and/or properties of these representations which are not seen when pencil
\end{abstract}

* Professora do ensino básico do Colégio Militar de Salvador. E-mail: avanirocha@gmail.com. 
and paper or the board are used. This could lead to more dynamic and lighter classes, which stimulate interest in the group and significantly change the role of the teacher in the learning process. This article highlights how a high school teacher can use the Winplot educational software in geometric constructions in order to visualize concepts and properties related to trigonometric functions.

Keywords: new technologies, educational software, trigonometry.

\section{Introduçáo}

O que é a Matemática e como se ensina é preocupação básica nas comunidades de educação matemática em todo o mundo. Diversos estudos apontam para o fracasso no ensino dessa matéria e sugerem renovaçóes na prática docente. Fatores como a preocupação dos professores em cumprir o conteúdo contido nos currículos, atividades em sala de aula que envolvem conceitos de difícil visualização para os alunos, resolução de número excessivo de exercícios repetitivos, além da notação ou terminologia matemática muito sofisticada e de difícil domínio, são apontados como provocadores de distorçóes no ensino-aprendizagem. Isso sugere que o professor precisa alterar esse quadro, modificando a sua proposta pedagógica, optando por práticas educativas que coloquem o aluno como centro do processo educacional, buscando novas formas de desenvolver conceitos.

Entendemos que não é mais aceitável assistir às aulas de Matemática de forma passiva. Ao contrário, acreditamos que a participação ativa representa a melhor forma de construir o conhecimento..., o aluno é convidado a discutir, a ouvir, a refletir, a conjecturar, enfim, a fazer matemática. (Longen, 2004, p. 3)

O uso das novas tecnologias de informação e comunicação (TIC) pode se prestar a esse fim, uma vez que elas têm contribuído com a humanidade para a transformação e interação com o universo. Já é fato consumado a importância e a necessidade de integração das tecnologias ao trabalho escolar, em especial as novas tecnologias da informação e comunicação, considerando que elas estão cada vez mais presentes no cotidiano, especialmente dos jovens, e que sua aplicação na educação, no trabalho e em outros contextos relevantes é uma competência básica a ser propiciada pelos educadores no conjunto do currículo escolar e de suas disciplinas. 
Para Tedesco (2004), a incorporação das novas tecnologias à educação deveria ser considerada como parte de uma estratégia global de política educativa e, ainda, que "as estratégias devem considerar, de forma prioritária, os professores", uma vez que "as novas tecnologias modificam significativamente o papel do professor no processo de aprendizagem e as pesquisas disponíveis não indicam caminhos claros para enfrentar o desafio da formação e do desempenho docente nesse novo contexto" (Tedesco, 2004, p. 11).

Mas como a escola pode capacitar os jovens se a formação inicial e continuada dos professores também náo os prepara para isso? Como os professores podem ampliar o potencial do seu trabalho escolar por meio de recursos tecnológicos se eles pouco sabem de suas potencialidades e limites? Por que, quando e como utilizá-las para dinamizar o processo de ensino e aprendizagem em sua disciplina?

A fim de colaborar com a busca de meios de renovação da prática pedagógica do professor de Matemática, elaborou-se este artigo com o objetivo de incentivar o uso crítico e consciente de novas tecnologias como ferramenta didática usando como exemplo o software educacional Winplot.

\section{A Informática e a Matemática}

O uso de novas tecnologias na escola pode reforçar a tentativa constante de solução das dificuldades encontradas no ensino da Matemática em qualquer nível de ensino, proporcionando uma motivação diferente das aulas teórico-expositivas e também trabalhando com o lado intuitivo de cada aluno. Em particular, a informática tem provocado revoluçóes nas relaçóes humanas e é capaz de propiciar ambientes com propostas pedagógicas de aprendizagem no ensino de matemática. A ferramenta computacional é uma das possibilidades de trabalho em sala de aula, ocupando, inclusive, papel de destaque nas orientaçóes expressas nos Parâmetros Curriculares Nacionais, que sugerem uma reflexão sobre a relação entre matemática e tecnologia, baseado nas necessidades de renovação de saberes.

A informática educacional, hoje, está implantada nas escolas de duas formas: para algumas, se adequarem às tendências da sociedade atual significa incluir no currículo uma disciplina de Informática e, para outras escolas, o uso do computador está relacionado às disciplinas do currículo. Os dois 
procedimentos atendem ao processo de ensino e aprendizagem, mas com enfoques distintos. $\mathrm{O}$ primeiro refere-se ao ensino e aprendizagem de computação - o computador é usado como objeto de estudo e objetiva desenvolver no aluno conceitos computacionais como: princípios de funcionamento da máquina, noções de programação, redes e outros. O segundo refere-se ao ensino e aprendizagem de conteúdos específicos das disciplinas - o computador é usado para a formação de conceitos científicos, numa abordagem pedagógica que objetiva o desenvolvimento cognitivo do aluno. Para incorporar esse recurso no processo de ensino e aprendizagem, várias estratégias têm sido adotadas. Uma delas é o desenvolvimento e aperfeiçoamento dos softwares educacionais.

Gravina e Santarosa (1998) apontam que a escolha de um software educacional para a aprendizagem matemática deve oferecer recursos que auxiliem o aluno na construção do conhecimento e superação de dificuldades por meio de atividades de expressão ou exploração. $\mathrm{Na}$ Expressão, o aluno cria um modelo, segundo suas ideias e pensamento, que servirá de base para a experimentação e reflexão sobre suas concepções, podendo ajustá-las ou modificá-las. Na Exploração, parte-se de modelos prontos com os quais o aluno vai interagir, manipulando-os, buscando compreendê-los, estabelecendo relaçóes e construindo conceitos.

Considerando-se essas abordagens, existem softwares, tais como planilhas eletrônicas (Excel), manipuladores simbólicos (Maple), pacotes específicos para determinados conteúdos curriculares, como o Skecthpad e Cabri (geometria), Gnuplot e Matgraph (gráficos), Rurci (álgebra e trigonometria), Winmat (matrizes), Winplot (funçóes) ou sistemas micromundo (Logo), que são bastante usados no âmbito da educação matemática.

Muitos desses softwares oferecem instâncias físicas em que a representação passa a ter caráter dinâmico, e isso, ainda segundo Gravina e Santarosa (1998), tem reflexos nos processos cognitivos, particularmente sobre as concretizaçóes mentais. O dinamismo é obtido com a possibilidade de se fazer manipulaçóes diretas sobre diferentes representaçóes visuais apresentadas na tela do computador, o que não ocorre com o uso do lápis e papel ou do quadro. As autoras citam como exemplo: "em geometria são os elementos de um desenho que são manipuláveis; no estudo de funções são objetos manipuláveis que descrevem relação de crescimento/decrescimento entre as variáveis" (Gravina e Santarosa, 1998, p. 11). 
Os programas para geometria apresentam o recurso de capturação de procedimentos (inventário), em que, automaticamente, são gravados os procedimentos do usuário em seu trabalho de construção. E, mediante solicitação, ele pode rever os passos para o desenvolvimento de sua construção ou construçóes desenvolvidas por outros. Isso permite ao usuário refletir sobre suas ações e ideias, compará-las com um outro processo ou ajustá-las.

Mais importante que o software, em si, é o modo como ele é utilizado. A escolha dele precisa fundamentar-se na proposta pedagógica de Matemática da escola (Hinostroza; Mellar, 2001). Sua adequação depende da forma como se insere nas práticas de ensino, das dificuldades dos alunos identificadas pelo professor e por análises das situaçôes realizadas com alunos para os quais o software é destinado. Cabe ao professor buscar aquele que pode adequar-se melhor às características do seu público.

\section{O professor e as novas tecnologias}

Perrenoud (2000) cita como uma das competências fundamentais do professor o conhecimento das possibilidades e o domínio dos recursos de informática existentes, por meio de uma atualizaçáo frequente e pela busca de novos meios educativos para uma melhor qualidade da aprendizagem.

Visto que a utilização da informática vem sendo um recurso alternativo para uma atuaçáo pedagógica de qualidade, dando suporte aos objetos matemáticos e às açóes mentais dos alunos, favorecendo os processos inerentes à construção do conhecimento matemático e ao desenvolvimento de estruturas cognitivas fundamentais na aprendizagem, faz-se necessário que o educador esteja capacitado para sua utilização, conhecendo o que essa ferramenta tecnológica tem a oferecer e como pode ser explorada em diferentes situaçóes educacionais.

Não basta que o professor saiba "como mexer no computador" e lidar com softwares, mas, sim, que compreenda quais as vantagens de sua utilização para a organização do pensamento e a socialização do educando. Seu papel é orientar, incentivar e questionar o porquê, o para que e o como, tanto no erro, quanto no acerto. Propiciar ao grupo a reflexão sobre o que produz contribui para desenvolver o pensamento lógico, estabelecer relaçóes, levantar hipóteses, testar alternativas, escolher caminhos, buscar e discutir as diferentes soluções, sistematizando-se, assim, seu próprio conhecimento. 
O professor que associa a tecnologia da informação e comunicação (TIC) aos métodos ativos de aprendizagem desenvolve a habilidade técnica relacionada ao domínio da tecnologia e, sobretudo, articula esse domínio com a prática pedagógica e com as teorias educacionais que o auxiliem a refletir sobre a prática e a transformá-la. (Almeida, 2005, p. 72)

\section{O software Winplot}

É um programa gráfico de propósito geral, que permite o traçado e animação de gráficos em 2D e em 3D, inclusive o de família de curvas, a partir de parâmetros adotados, por meio de diversos tipos de equaçóes (explícitas, implícitas, paramétricas, e outras). O Winplot faz parte da Peanut Softwares, uma coleção de softwares matemáticos, todos gratuitos criados por Richard Parris. É de uso relativamente simples e tem versóes em vários idiomas, inclusive em português. Na homepage da Peanut Softwares (http://math.exeter.edu/rparris/), há um link para a página do Winplot (http://math.exeter.edu/rparris/winplot.html).

Uma das maiores riquezas no uso desse software é realizar construçóes geométricas como numa folha de papel e ser capaz de movimentá-las. O caráter dinâmico gera vantagens para o ensino, como a de acelerar o tempo das construções, encorajar a tentativa e erro, construir figuras geométricas mais trabalhosas, além de permitir conjecturas e simulaçôes de situações que não poderiam ser exploradas com lápis e papel. A possibilidade de movimento permite a criação de um ambiente intrigante de investigação. Batista et al. (2004) avaliaram o seu uso no ensino médio e classificaram-no como de instalação simples, dotado de recursos bastante adequados aos critérios pedagógicos gerais e também àqueles relativos aos Parâmetros Curriculares Nacionais para o Ensino Médio (PCNEM) (bloco D). Foi atestado que é um software direcionado a uma linha construtivista de educação e seus recursos favorecem a construção de conhecimentos matemáticos, permitindo estabelecer conjecturas a partir da visualização da movimentação de gráficos, possibilitando, assim, a exploração de diversos conteúdos.

\subsection{O uso do Winplot para o estudo de Trigonometria}

Os recursos gráficos do Winplot permitem as mais variadas explorações do ciclo trigonométrico e das funçôes trigonométricas desde que se 
conheça a matemática necessária (equação da circunferência e coordenadas polares também são necessárias) para a construção das figuras.

Com o uso desse programa gráfico, pretende-se: relacionar o estudo do seno, cosseno e tangente no triângulo retângulo com o ciclo trigonométrico e apresentar a tangente nesse ciclo e, ainda, explorar ângulos do ciclo trigonométrico, medidos em graus ou radianos e algumas das propriedades de seno e cosseno nesse ciclo a partir da análise dos valores assumidos em diversas posiçóes; representar graficamente as funçóes seno, cosseno e tangente.

Para atingir esses objetivos, foi usada a manipulação da figura, por meio de animaçóes, para familiarização com as transformaçóes da medida de um ângulo de radiano para grau, bem como com as medidas de seno, cosseno e do próprio ângulo por meio de números decimais.

Os conceitos envolvidos nessas atividades, entre outros, são: triângulo retângulo, seno, cosseno, tangente, ângulos, arco, medidas de ângulos, graus, radianos, ciclo trigonométrico, funçáo seno, cosseno e tangente.

Algumas construçóes propostas para o estudo da trigonometria estão representadas nas figuras que se seguem. Excetuando-se as figuras 1 e 2, todas as outras representam janelas em que foi usado o recurso da animação.

As razóes trigonométricas seno, cosseno e tangente de um ângulo agudo de um triângulo retângulo dependem da medida do ângulo e não do tamanho dele. Considerando-se triângulos retângulos com hipotenusas de mesma medida (Figura 1), observa-se que os vértices B, C, D e E pertencem à mesma circunferência. Adotando-se a unidade para medida da hipotenusa, o seno e o cosseno de um ângulo agudo de vértice $\mathrm{O}$ serão, respectivamente, a medida do cateto oposto e a medida do cateto adjacente a esse ângulo.

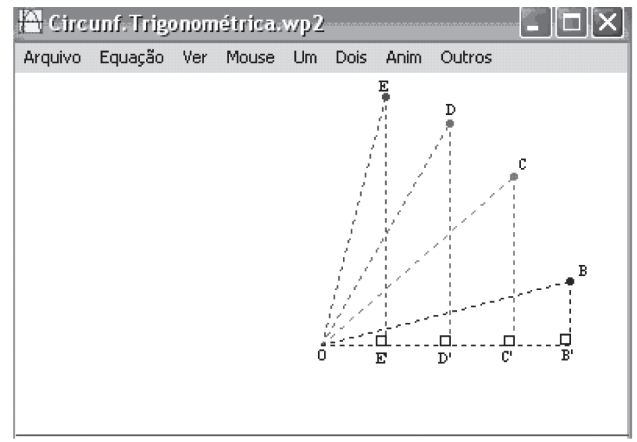

Fig. 1 - Triângulos Retângulos

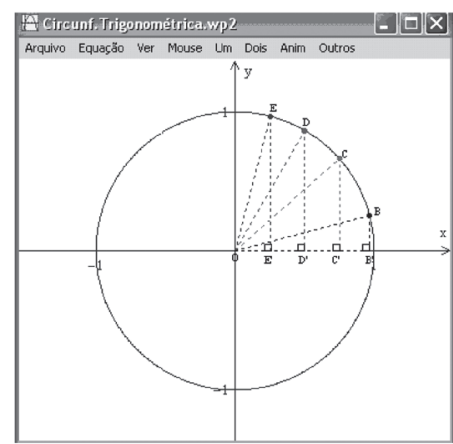

Fig. 2 - Ciclo Trigonométrico 
A partir dessas ideias, foram definidas as razōes trigonométricas em um sistema denominado ciclo trigonométrico, visto na Figura 2, no qual os conceitos de seno, cosseno e tangente são ampliados para ângulos maiores ou iguais ao ângulo reto.

As Figuras 1 e 2 estão na mesma janela e podem ser exibidas separadas. O programa oferece o recurso de esconder gráficos, permitindo que se faça toda a construção e a exiba aos poucos, o que agiliza e facilita a explanação.

As convençôes no ciclo trigonométrico podem ser vistas na Figura 3. A animação da figura permite a visualização da origem de todos os arcos (ponto A), de arcos nos sentidos horário e anti-horário e do quadrante ao qual pertence a extremidade do arco.

As medidas em graus ou radianos dos principais arcos do ciclo trigonométrico, nos dois sentidos, podem ser escritas na tela por meio do recurso de texto oferecido pelo software.

Ao parar a animação, tem-se, na janela do valor usual do parâmetro, o número real decimal associado à extremidade do arco na primeira volta.

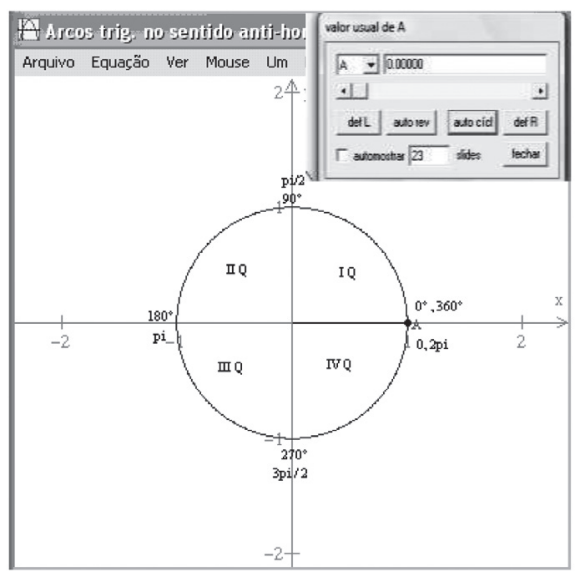

Fig. 3 - Convençôes no Ciclo Trigonométrico (sentido anti-horário)

A Figura 4 relaciona um arco de medida $c$, no sentido anti-horário, com seu comprimento em radianos representado no eixo x, cuja escala está em múltiplos de $\pi / 6$. O número real associado ao ponto que é extremidade 
do arco, na primeira volta, é visto na janela do valor usual do parâmetro utilizado e pode ser usado para conversão da medida em graus.

Dois arcos trigonométricos são côngruos se, e somente se, suas extremidades coincidem. Extremidades e medidas em radianos de arcos das primeira e segunda voltas são visualizadas com a animação da Figura 5, e, consequentemente, pode-se explorar o conceito de arcos côngruos, o quadrante em que se situa determinado arco da segunda volta e sua menor determinaçáo positiva. Arcos da terceira volta também podem ser trabalhados ajustando-se a fonte para um tamanho em que se possa ter uma escala nítida.

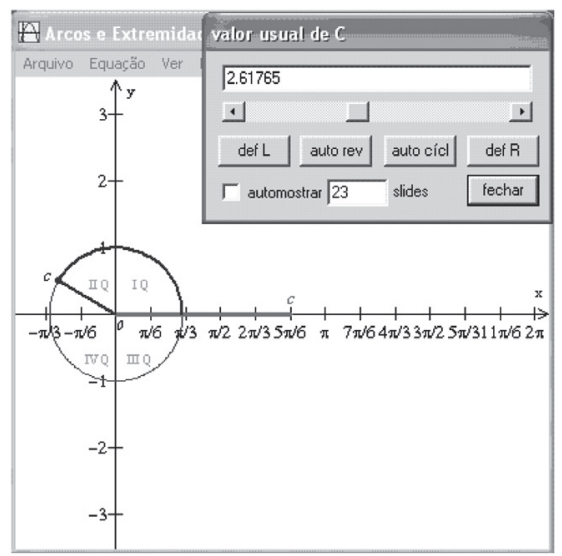

Fig. 4 - Medidas de Arcos em Radianos

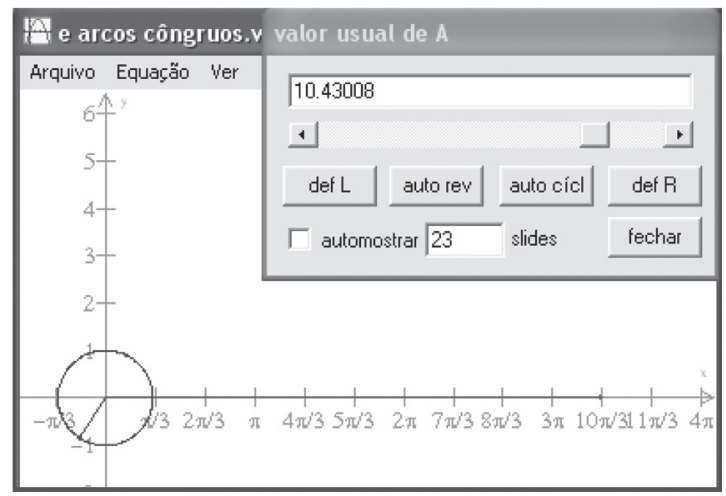

Fig. 5 - Arcos Côngruos 
Três tipos de simetria no ciclo trigonométrico são exibidos na $\mathrm{Fi}$ gura 6: em relação ao eixo vertical, em relação ao eixo horizontal e em relação à origem do sistema. A animação dos segmentos enfatiza quais as extremidades simétricas à de um arco do $1^{\circ}$ quadrante de medida $x$, facilitando a obtenção e a generalização das medidas dos arcos correspondentes no $2^{\circ}, 3^{\circ}$ e $4^{\circ}$ quadrantes.

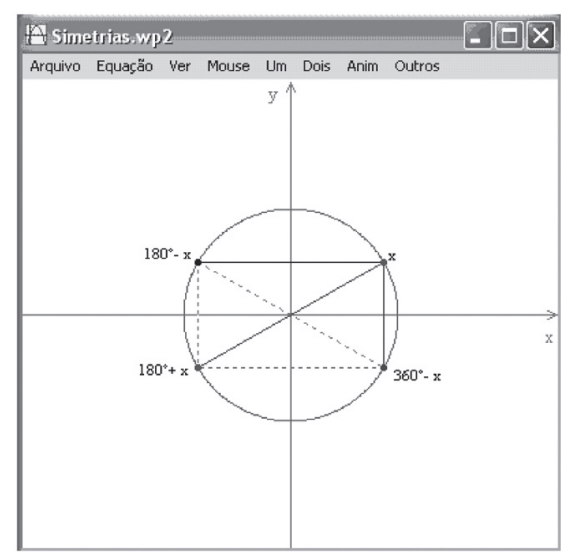

Fig. 6 - Simetrias

A definição de cosseno e seno de um arco trigonométrico como a abscissa e a ordenada, respectivamente, do ponto que é a extremidade do arco, pode ser inferida observando-se a Figura 7. Nela, percebe-se que as medidas dos catetos adjacente e oposto ao ângulo central determinado pelo arco AP correspondem às coordenadas do ponto $\mathrm{P}$, extremidade do arco. Dessa forma, estende-se esse conceito de cosseno e seno a qualquer arco trigonométrico.

O programa fornece as coordenadas de qualquer ponto da circunferência, ativando-se esse recurso no mouse, e também podem ser visualizados, para qualquer arco, os segmentos que representam as medidas $\cos (\mathrm{x})$ e $\operatorname{sen}(\mathrm{x})$. Parando-se a animação, tem-se a representação geométrica e o valor numérico do cosseno e do seno de um determinado arco trigonométrico, podendo-se verificar a relação fundamental da trigonometria. 
Os valores mínimo e máximo e a variação de sinal do seno e do cosseno podem ser vistos por meio da animação dos segmentos que os representam, simultaneamente com o arco correspondente.

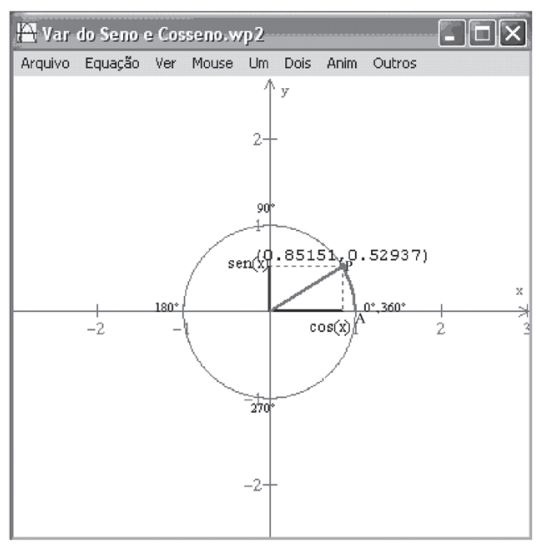

Fig. 7 - Seno e Cosseno de Arco Trigonométrico

Para encontrarmos a tangente de um arco trigonométrico, devemos considerar a reta $t$ (eixo das tangentes) perpendicular ao eixo das abscissas pelo ponto A e prolongar o raio que passa pela extremidade do arco até a intersecção com essa reta, o ponto T, como mostra a Figura 8.

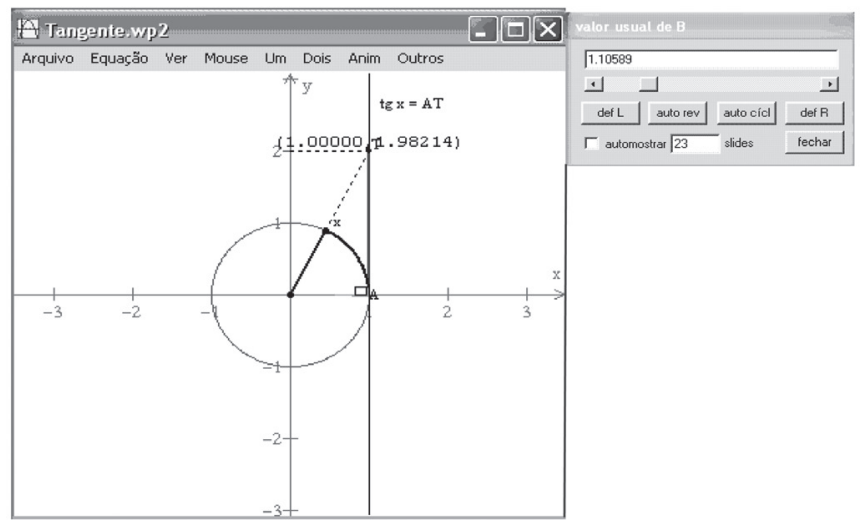

Fig. 8 - Tangente de um Arco Trigonométrico 
No triângulo retângulo OAT, a tangente do ângulo central determinado pelo arco de medida $x$ é a medida do segmento AT, sendo esta a ordenada do ponto T. Temos, então, que a tangente de um arco trigonométrico é a ordenada do ponto obtido pela intersecção do prolongamento do raio que passa pela extremidade do arco com o eixo das tangentes.

Com a animação da Figura 8, representa-se geometricamente a tangente de qualquer arco para o qual ela exista e observa-se sua variação de sinal. Parando a animação, tem-se a medida do arco em radianos e o valor decimal da tangente.

As Figuras 9, 10 e 11 mostram que a cada número real x podemos associar um único seno, um único cosseno e, obedecida a condição de existência, uma única tangente. Definem-se, assim, as funçôes trigonométricas $\mathrm{f}(\mathrm{x})=\operatorname{sen} \mathrm{x}, \mathrm{g}(\mathrm{x})=\cos \mathrm{x}$ e $\mathrm{h}(\mathrm{x})=$ tg $\mathrm{x}$ e seus respectivos domínio e imagem.

$\mathrm{Na}$ Figura 9, temos um ponto genérico do tipo $(\cos \mathrm{x}$, sen $\mathrm{x})$ no círculo trigonométrico e os correspondentes pontos da forma ( $\mathrm{x}$, sen $\mathrm{x}$ ) descrevendo a função seno. Na Figura 10, temos um ponto genérico da forma $(\cos \mathrm{x}, \operatorname{sen} \mathrm{x})$ no círculo trigonométrico e os correspondentes pontos da forma $(\mathrm{x}, \cos \mathrm{x})$ descrevendo a função cosseno. A animação nessas figuras é relevante ao estudo das relaçóes entre o seno e o cosseno de um número real $\mathrm{x}$ e as coordenadas da extremidade de um arco de $\mathrm{x}$ radianos sobre uma circunferência, permitindo uma compreensão lúdica e rápida das importantes ideias de período, fase e amplitude de um movimento periódico.
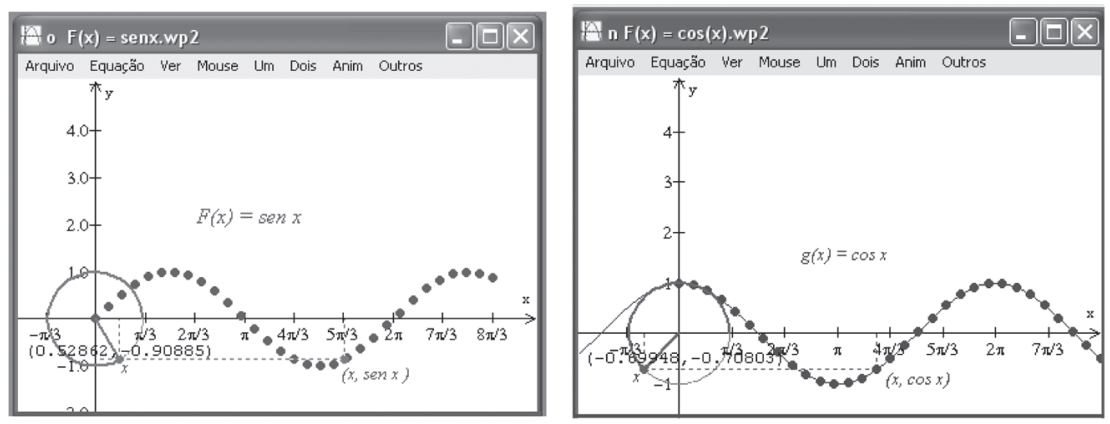

Figs. 9 e 10 - Função Seno e Ciclo Trigonométrico; Função Cosseno e Ciclo Trigonométrico 

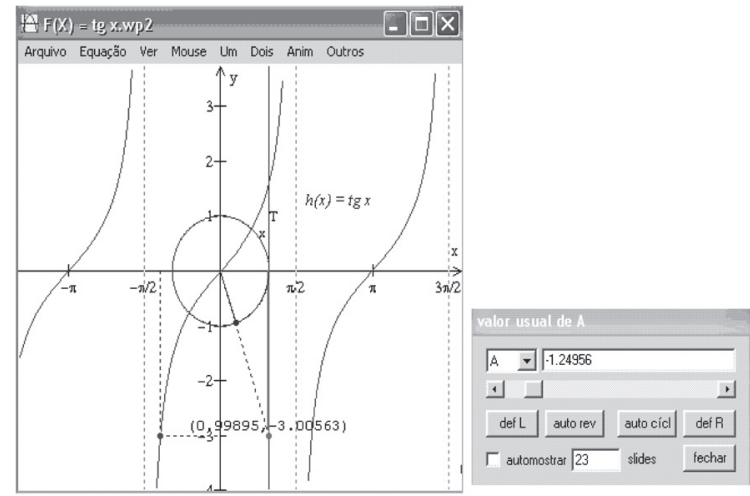

Fig. 11 - Função Tangente e Ciclo Trigonométrico

A possibilidade de variação da escala nos gráficos das Figuras 9, 10 e 11 permite a melhor visualização do período das funçóes, facilitando a verificação de propriedades como $\operatorname{sen}(k 2 p+x)=\operatorname{sen} x$.

Outros tópicos relativos à trigonometria podem ser trabalhados com o uso do Winplot. Neste artigo, foram abordados apenas aqueles que a autora, como professora de Matemática do Ensino Médio, julgou mais relevantes para a introdução do assunto. Cabe ao professor conhecer o software e adequar o seu uso à sua necessidade e à de seus alunos.

\section{Conclusão}

A utilização do Winplot torna mais fácil construir figuras que, se fossem feitas "a mão", talvez não permitissem aos alunos ver algumas importantes características e/ou propriedades das razóes trigonométricas. A aula torna-se mais dinâmica e lúdica, estimulando o grupo e despertando o interesse.

Todavia, o computador não substitui o professor de Matemática, apenas modifica algumas de suas funçóes. A tarefa de passar informaçóes pode ser dividida com os bancos de dados: Internet, bibliotecas virtuais, livros, vídeos, softwares e outros. O professor passa a ser o estimulador da curiosidade e da criatividade do estudante, na busca de informaçóes relevantes. Seu papel é orientar, incentivar e questionar o porquê, o para que e o como, tanto no erro quanto no acerto. Propiciar aos educandos a reflexão sobre o que produz contribui para desenvolver o pensamento lógico, 
estabelecer relaçóes, levantar hipóteses, testar alternativas, escolher caminhos, buscar e discutir as diferentes soluções, construindo-se, assim, seu próprio conhecimento. Para isso, o professor precisa buscar a capacitação para dominar os recursos tecnológicos, elaborar atividades de aplicação desses recursos, escolhendo os mais adequados aos objetivos pedagógicos, analisar os fundamentos dessa prática e as respectivas consequências produzidas em seus alunos.

O uso do computador no processo de ensino e aprendizagem de Matemática deve objetivar a complementação e/ou integração do trabalho no laboratório com a sala de aula. Sua utilização deve estar vinculada a análises reflexivas de uso e aplicabilidade na prática pedagógica.

$\mathrm{O}$ aprendizado com o auxílio do software é superior às propostas convencionais, entretanto é válido ressaltar a importância do domínio do conteúdo matemático como única maneira de fazer o computador oferecer as respostas de que se necessita para uma verdadeira compreensão de determinado tópico. Assim, o desenvolvimento de atividades no uso de um software educacional implica integrar o conhecimento matemático com o conhecimento informático, associado ao desenvolvimento de habilidades.

É importante que a escola ofereça infraestrutura e os recursos necessários para renovação da prática do professor.

Outras razões trigonométricas, algumas equações, identidades e funçóes podem ser exploradas com uso do Winplot. Com o conhecimento dos recursos do software, criatividade e disposição, o professor tem grande possibilidade de melhorar a qualidade da sua prática pedagógica.

\section{Referências}

ALMEIDA, M. E. B. de. Tecnologia na escola: criaçáo de redes de conhecimentos. In: BRASIL. Ministério da Educação. Secretaria de Educação a Distância. Integração das tecnologias na educação. Brasília: MEC/SEED, 2005.

BATISTA, S. C. F.; BARCELOS, G. T.; RAPKIEWICZ, C. E.; HORA, H. R. M. Avaliar é Preciso: o caso de softwares educacionais para Matemática no Ensino Médio. 2004. Disponível em : <http://inf.unisul.br/-ines/ workcomp/cd/pdfs/2378.pdf>. Acesso em: 14 jun. 2008. 
BRASIL. Secretaria de Educação Fundamental. Parâmetros Curriculares Nacionais: Introdução. Brasília: MEC/SEF, 1998.

GRAVINA, M. A.; SANTAROSA, L. M. C. A Aprendizagem da Matemática em Ambientes Informatizados - Informática na Educação. Teoria e Prática. v. 1, n. 1. Porto Alegre: UFRGS - Curso de Pós-Graduação em Informática na Educação, 1998.

HINOSTROZA, J. E.; MELLAR, H. Pedagogy embedded in educational software design: report of a case study. Computers \& Education, 37, 2001. p. $27-40$.

LONGEN, A. Matemática no Ensino Médio. Curitiba: Positivo, 2004. p. 224.

PERRENOUD, P. Dez novas competências para ensinar. Porto Alegre: Artes Médicas Sul, 2000.

TEDESCO, J. C. (Org.). Educação e novas tecnologias: esperança ou incertezas. São Paulo/Buenos Ayres/Brasília: Cortez/Instituto Internacional de Planeamiento de la Educación/UNESCO, 2004. p. 11.

Recebido em: 26 maio 2010

Aceito em: 25 jun. 2010 